\title{
Perspectivism in current epigenetics
}

\author{
Karim Bschir ${ }^{1}$
}

Received: 21 October 2019 / Accepted: 2 March 2020 / Published online: 17 September 2020

(C) The Author(s) 2020

\begin{abstract}
Discussions about perspectivism in the current philosophical literature often focus on questions concerning perspectival modeling or the compatibility between perspectivism and realism. In this paper, I propose to extend the debate on perspectivism by taking into account the social dimension of scientific perspectives. Scientific perspectives are always adopted and advocated for by individual scientists and groups of scientists with different epistemic affinities. I describe an example of a current and ongoing controversy in the field of epigenetics in order to illustrate that diverging scientific perspectives on open scientific questions are often not fully explained by empirical underdetermination or diverging theoretical approaches alone. Opposing perspectives frequently arise from differences in systems of practice and the scientific socializations of the involved scientists, including differences in training, experimental skills, and epistemic priorities. The paper ends with a discussion of the important epistemic function of perspectives in scientific discovery. Ultimately, perspectivism is described as a valid philosophical position that explains how scientific knowledge is generated in situations of empirical underdetermination and why trust in science can be justified even in the absence of a community consensus.
\end{abstract}

Keywords Perspectivism - Epigenetics $\cdot$ Systems of practice $\cdot$ Disagreement

\section{Introduction: from perspectival models to perspectival practices}

The basic idea of perspectivism in the philosophy of science is to highlight the perspectival character of scientific knowledge. Another way to put it would be to say that perspectivism is a philosophical position that views all scientific knowledge claims as essentially contextual. Or to frame it negatively: perspectivism denies the existence

This article belongs to the Topical Collection: Perspectivism in science: metaphysical and epistemological reflections

Guest Editor: Michela Massimi

Karim Bschir

karim.bschir@unisg.ch

1 University of St. Gallen, St. Gallen, Switzerland 
of what Ernest Nagel famously called a "view from nowhere" that would provide a neutral and objective standpoint from which diverging scientific knowledge claims can be judged (Nagel 1986). The consequence of denying the existence of such an objective standpoint is to say that all scientific knowledge, all scientific theories and frameworks, provide perspectives on reality from within specific contexts. Michela Massimi describes perspectivism as a "family of positions that in different ways place emphasis on our scientific knowledge being situated" (Massimi 2018c, p. 164).

One may also try to capture the essence of scientific perspectivism by looking at its predecessors in the philosophical tradition. Perspectivism has two main historical origins: The first is Kant's transcendental idealism and the second is pragmatism. With pragmatism perspectivism shares the idea that science must be understood first and foremost as a human activity and that scientific knowledge should be seen in the first place as the product of such an activity. Hasok Chang recently provided an excellent analysis of the pragmatist roots of current perspectivist positions (Chang 2020). With Kant's philosophy perspectivism shares the emphasis on the active and constructive contribution of the human mind in the making of phenomena and thus in the production of empirical knowledge (Massimi 2018d).

In the recent literature, perspectivism has been proposed in different varieties for example in the form of perspectival realism by Ron Giere, who draws on elements in Thomas Kuhn's theory of scientific change (Giere 2006; see also Giere 2013 and Teller 2020) or in Bas van Fraassen's perspectivist account of scientific representation (van Fraassen 2008). There is, however, no commonly accepted definition in the current literature about what philosophical position the term "perspectivism" exactly denotes (see Massimi and McCoy 2020, p. 2). Despite a missing universally accepted definition of what it means to take a perspectivist position, one thing is hardly controversial, namely that perspectivism in one way or the other implies some sort of epistemic pluralism.

A more contested question concerns the compatibility of perspectivism with realism (and hence also of perspectivist pluralism with realism). In fact, the relationship to realism is one of the most discussed issues in the current philosophical literature on perspectivism. The topic is often treated in the context of the so called problem of inconsistent models (Morrison 2011). The problem arises in situations where several inconsistent models provide approximately true, partial de re representations of a given target system. Such models veridically represent certain essential properties of the target system while being inconsistent with other models that veridically represent a different set of essential properties of the same target system (the example discussed by Morrison (2011) is the family of different physical models of the atomic nucleus such as the liquid drop model, the shell model or the quark model.) Attempts to interpret such a situation in a realistic manner quickly lead to a dilemma. Either one claims that while not all the models can be equally true at the same time, there must be one single model that truthfully describes the target, whether it is in the currently available set of models or not; or one gives up the claim that scientific models are veridical representations of physical systems altogether. Either way the problem of inconsistent models poses a challenge to the realist.

Perspectivism is often brought forward as a way out of this conundrum. Recently, Michela Massimi has proposed an account of perspectival modeling in order "to show 
that perspectival modeling — suitably reinterpreted — can deliver on the quest for realism without abdicating on pluralism" (Massimi 2018b, p. 338). Massimi's account of perspectival models has three main components. First, it reinforces the realist intuition that models have sui generis representational content (i.e. they are "about" the system under scrutiny). Second, the representational character of the models must not be understood in terms of some mapping relation, as a widely held view about model representation has it. And third, the relation between the various models and the target system must be understood as a modal one, such that the primary function of the models is to help explore and understand what is possible and what is impossible in the system. Ultimately, perspectival models are supposed to advance our understanding of reality in the sense that they explore the possibilities of what entities, structures, or processes might or might not exist within the system under scrutiny. Massimi writes: "The realist quest can be vindicated when one considers the indispensable role that such a plurality of perspectival models plays in advancing our knowledge of what might be real (i.e., what kind of fundamental particles might or might not exist" (Massimi 2018b, p. 338).

To be sure, the perspectivist approach to the problem of inconsistent models does not stand uncontested and non-perspectivist alternatives have been proposed (see e.g. Chakravartty 2010 or Saatsi 2020). While these are fruitful philosophical debates that highlight important aspects of scientific modelling, representation, realism and the role of contextuality in science, they take away focus, as I will argue in the following, from another crucial aspect of perspectivism, namely the fact that perspectives are held and advocated for by individuals and groups of individuals with different epistemic affinities, background beliefs or scientific training. Scientific perspectives are tightly linked to the actual human beings engaged in specific research activities who adopt those perspectives. That is to say that scientific perspectives also have a social dimension attached to them and that philosophical discussions about perspectivism should include an analysis of that social dimension. While individual scientists may well be capable of adopting diverse perspectives and not all perspectives are incompatible, scientific controversies that arise from conflicting perspectives cannot be properly understood if one misses the social aspects of scientific perspectives.

In the following I thus intend to shift the focus away from questions related to perspectival modeling and the compatibility of perspectivism with realism towards an analysis of scientific perspectives in a broader sense, a sense that includes the social and practical aspects of scientific perspectives. This means a shift away from a view of perspectivism in terms of perspectival models to an account of scientific practices as perspectives. This is in line with Michela Massimi's description of a scientific perspective as "the actual-historically and intellectually situated-scientific practice of a real scientific community at a given historical time", which includes "the experimental, theoretical, and technological resources available to the scientific community at the time" (Massimi 2018a, p. 15). I suggest to call this the "practices as perspectives" view.

My understanding of "practices" in this contexts is congruent with Hasok Chang's definition of a system of practice: "A system of practice is formed by a coherent set of epistemic activities performed with a view to achieve certain aims" (Chang 
2012, p. 16). Chang also uses the term "systems of knowledge" interchangingly with "systems of practice". Chang's definition is useful because it highlights two crucial aspects of scientific practices: First, it captures scientific practices as activities that are oriented towards specific practical or epistemic aims (note the whiff of pragmatism). As I will argue in more detail later, this is one of the most crucial advantages of linking perspectives to practices. It helps to understand that scientists adopt certain perspectives, because they are pursuing specific epistemic goals, and that differences in perspectives are rooted in differences concerning the goals that are pursued by different groups of researchers. The second advantage of Chang's definition is its focus on epistemic practices. These include reports of experience, definitions of concepts, adoption of enabling assumptions, and logical deductions (Chang 2012, p. 242). One may also think of practices that are related to the collection and interpretation of empirical evidence: experimental methods and methods of measurement, statistical methods for data testing, and the interpretation of measurements and empirical findings. In the most general sense, epistemic activities include virtually everything that scientists $d o$ : describing, predicting, explaining, hypothesizing, testing, observing, detecting, measuring, classifying, representing, modeling, simulating, synthesizing, analyzing, abstracting, idealizing (Chang 2012, p. 16).

In order to highlight the necessity of linking perspectives with practices and of developing an account of perspectival practices, I present in the following two sections a case study of a current and ongoing scientific controversy between two opposing camps in the field of epigenetics - the mechanist camp on one side and the phenomenologist camp on the other. The goal of the case study is to show that this controversy can be understood and analyzed in terms of two rivaling scientific perspectives. Each of these perspectives is associated with different systems of practice that include different epistemic activities and goals. A discussion of the benefits and problems of a practice-centered account of perspectivism follows in Section 4.

Before I turn to the case study, let me also note the obvious fact that the purpose of the present paper is more programmatic than it is systematic. It is not supposed to be a contribution to the above mentioned discussion about perspectival modeling or about the compatibility between perspectivism and realism. Nor do I intend to take sides in the scientific controversy outlined below. The analysis at hand must be understood as a plea for the inclusion of aspects of scientific practices and social epistemology in current debates about perspectivism.

\section{Varying perspectives in current epigenetics}

The term "epigenetics" in the broad sense refers to the study of the influence of environmental factors on biological heredity. Before the modern synthesis of evolutionary theory in the early decades of the $20^{\text {th }}$ century, the fact that environmental factors acting on parents can have an influence on the phenotypes of their progeny was a common theme in theories of heredity and evolution. "Heredity is only the sum of all past environment." This statement by the American Botanist Luther Burbank from his 1906 book The training of the human plant (Burbank 1906) nicely expresses this widely held view among biologists at the time. With the emergence 
of Neo-Darwinism, however, the dogma shifted and it became commonly accepted that acquired phenotypic changes cannot possibly affect genotypes and therefore are not transmitted to later generations. The underlying principle behind this idea was August Weismann's theory of the germ plasm according to which somatic cells are separated from germ cells and environmentally-induced changes in the somatic cells would not be transferred to germ cells (Weismann 1892).

The term "epigenetics" was coined by the British embryologist Conrad Hal Waddington in 1942 (Waddington 1942) in reference to Valentin Haecker's "Phenogenetics" (Haecker 1918). However, it is important to note that Waddingtion used the term to refer to the complex interaction between genotype and phenotype during development and not for the heredity of acquired phenotypic traits. A common definition coins epigenetics as "the study of mitotically and/or meiotically heritable changes in gene function that cannot be explained by changes in DNA sequence" (Riggs and Porter 1996). Several other definitions have been brought forward. ${ }^{1}$

For the purposes of this article, epigenetic inheritance will be understood as the alteration of gene expression patterns across meiotic cell divisions and across generations without changes in DNA sequence. It is, however, important to distinguish truly transgenerational epigenetic effects from merely intergenerational ones. Both types of inheritance are epigenetic insofar as they refer to effects that are not DNAencoded. Intergenerational (also called parental) effects include only those types of inheritance in which the developing embryo or its germline is exposed in utero to the same environmental changes as the parent. Typically these are changes in nutritional supply, hormonal effects, or environmental toxin exposure. Because such environmental triggers can affect the embryo's germline, their consequences can, under special circumstances, also be observed in the next generation (i.e. the grandchildren of the exposed parent). Intergenerational effects on grandchildren are therefore always necessarily maternal. Only if also the grand-grandchildren (F3) exhibit the acquired phenotypic trait, one may speak of a truly transgenerational epigenetic effect, because only in this case, the trait acquired in the F0 parent has been transmitted transgenerationally. If the male parent gets exposed to the environmental trigger a truly transgenerational effect can occur already in the F2 generation, because there is no possibility of the embryo being exposed and the trigger directly effects the epigenome of the the father's germline (see Fig. 1).

Several molecular mechanisms have been proposed for transgenerational epigenetic inheritance. The most important are:

- DNA methylation and other chromatin-related mechanisms

- mRNA and protein feedback loops

- non-coding RNAs

- prions

DNA methylation describes the activation and deactivation of genes during development through the alteration of the methylation state of selected DNA segments. DNA

\footnotetext{
${ }^{1}$ See e.g. Bird (2007) or Felsenfeld (2014); and Stotz and Griffiths (2016) for different meanings of "epigenetics". Baedke (2018 ,p. 7) describes "epigenetics" as a "cluster concept".
} 


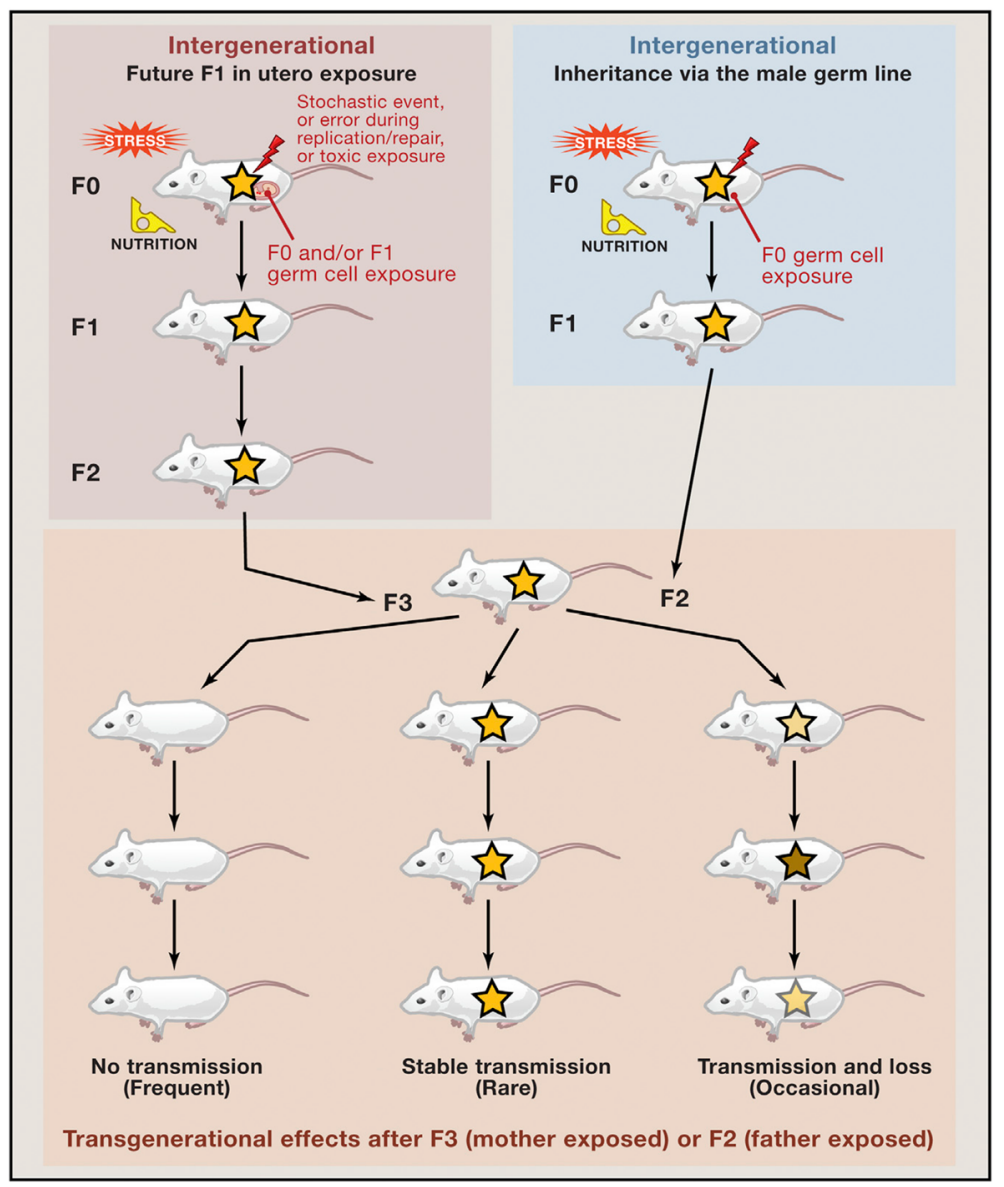

Fig. 1 Comparison between inter- and transgenerational epigenetic effects via the male or female line. Reprinted from Heard and Martienssen (2014, p. 97) with permission from Elsevier

methylation together with histone modifications is one of the best studied mechanisms for transgenerational epigenetic inheritance. However, it remains unclear how stable these modifications are during development and to what extent they are species-specific. It has been suggested that mRNA and protein feedback loops can also induce heritable states, but, again, the stability of the alteration of gene expression via such loops is a matter of ongoing investigation. Other promising candidates for a molecular carrier of epigenetic information are small RNAs and long noncoding RNAs that interfere in transcription and translation and are involved in DNA and histone modification. More recently, the role of prions, i.e. proteins that act as structural templates for other proteins, in epigenetic inheritance is increasingly studied, in particular in fungi.

Talking about the potential mechanisms of epigenetic inheritance, one should not forget to also mention confounding factors. As it is often the case in experimental 
studies of molecular mechanisms, the study of epigenetic inheritance likewise requires a careful examination of a variety of causal factors that could interfere with the mechanism under scrutiny. In the case of epigenetic inheritance, these factors include a phenomenon called germline reprogramming, whereby the DNA methylations (among other DNA modifications) in parental gamets become removed and reset during embryonic development. ${ }^{2}$ Understanding the reprogramming of the parental epigenome during development is crucial if one is interested in the hereditary stability of epigenetic states. Other confounding factors are parental behavioral effects that can induce heritable changes in the progeny's nervous system, such as diet, exposure to chemicals due to behavioral patterns etc., or the transmission of information across generations via the microbiome, which is also linked to behavioral factors (Heard and Martienssen 2014, p. 99). It is important to note that post-natal parental effects are sometimes treated not as confounding factors, but as genuine intergenerational effects that are on the same level as in utero effects. This merely shows the fluidity of the definitions involved in the study of epigenetic inheritance.

Confounding factors render the study of the molecular mechanisms underlying epigenetic inheritance an inherently difficult task. Isolating the causal factors that are involved in the transmission of epigenetic information over several generations in living organisms requires an extensive control of the experimental environment. This makes epigenetics a challenging, but also highly attractive field of research. But epigenetics is not only attractive because of the interesting experimental problems it poses. Epigenetics is an interesting and dynamic subfield of current biological research for several other reasons. First, epigenetics has a paradigm-shattering potential. As mentioned earlier, new epigenetic findings could potentially replace decade-old biological paradigms, such as the idea of the "Weissmann barrier", i.e. that hereditary information can only flow from germ cells to somatic cells and never the other way. Second, epigenetics carries a lot of public appeal. It may be assumed that the number of popular books, magazine and newspaper articles, documentaries and television pieces on epigenetics far exceeds the number of contributions on other domains of current biological research. The reason for this is quite obvious: If science could prove that our behavioral habits and the environmental influences that we experience during our lifetime can have manifest biological effects on later generations, this would have far reaching consequences not only biologically, but also for our broader understanding of human nature. Last but not least, epigenetics stands out as a field of research because of its high degree of interdisiplinarity. Epigenetics attracts researchers from a variety of biological sub-disciplines such as molecular biology, genetics (and plant genetics in particular), developmental biology, evolutionary biology, epidemiology, medicine, neurobiology and psychology.

The latter point also renders epigenetics a highly interesting subject for philosophical investigation. Because research in epigenetics is done by scientists with a variety of disciplinary backgrounds, theoretical interests and methodological affinities, interestingly enough the answer to the most basic question in epigenetics-whether

\footnotetext{
${ }^{2}$ See Monk (2015) or Leitch et al. (2013).
} 
transgernarational epigenetic inheritance exists in mammals and if so how stable it is-varies with the disciplinary background of the involved scientists, as will be shown in the following.

\section{Phenomenologists vs. mechanists}

As mentioned earlier and as it is indicated in Fig. 1, the heritable stability of transgenerational epigenetic information remains a matter of scientific investigation. Different scientists offer varying assessments of how relevant epigenetic effects are, especially in mammals. If asked for their opinion as to "[h]ow much epigenetic inheritance takes place", leading scientists in the field provide the following answers: ${ }^{3}$

[Quote 1 by a pediatric geneticist, who studies environmental epigenomics and human transgenerational responses]

Molecular evidence for transgenerational epigenetic inheritance in humans is limited, but I suspect that it is commonplace. Transgenerational epigenetic inheritance is the best candidate mechanism to explain the male-line transgenerational effects that are now being demonstrated within cohort studies capable of dealing with many social and other confounders. If these observations are statistically sound and cannot be explained by genetic or cultural inheritance, then this is transgenerational epigenetic inheritance in its broadest sense.

[Quote 2 by a developmental geneticist, who studies genomic imprinting and environmental epigenetic effects in mammals]

The impact of the environment has been observed to extend over multiple generations in both human populations and animal models, suggesting transgenerational epigenetic effects. However, a defined mechanism for such inheritance is missing.

What is interesting about these statements is the fact that it is admitted that "[m]olecular evidence for transgenerational epigenetic inheritance in humans is limited" and that "a defined mechanism for such inheritance is missing", but nevertheless epigenetic inheritance is viewed as "commonplace" and that "the impact of the environment has been observed to extend over multiple generations." Furthermore, in quote 1, epigenetic inheritance is taken to be the best explanation for a variety of "statistically sound" observations. In terms of its inferential structure, this statement amounts to an inference to the best explanation, for it proposes the existence of stable epigenetic inheritance as the only viable explanation for certain observable correlations.

In opposition to the above statements, we also find claims like the following:

\footnotetext{
${ }^{3}$ All the following quotations are taken from (Grossniklaus et al. 2013). This paper published in Nature Reviews Genetics contains the answers four leading scientist working in epigenetics to two questions: 1) How much transgenerational epigenetic inheritance takes place? 2) How much impact does transgenerational epigenetic inheritance have on organisms? All four scientist are listed as co-authors of the paper. The following quotes are excerpts from these answers.
} 
[Quote 3 by a plant geneticist, who studies the genetic and molecular basis of plant reproduction]

In mammals, only very few-sometimes controversial-cases of meitotically inherited epialleles have been reported, mostly with a variable degree of inheritance.

[Quote 4 by a plant geneticist, who studies the genetic and molecular basis of plant reproduction]

In principle, many inherited traits could have an epigenetic basis, as one cannot easily distinguish whether a phenotype is due to genetic or epigenetic variation without a detailed molecular analysis. It is also possible that epigenetically controlled traits are rare.

Scientists who make this second type of statements cast a general doubt on the very reality of epigenetic inheritance especially in mammals and ipso facto in humans. At least they leave room for the possibility that we are facing a very rare phenomenon, which is the exact opposite of calling it "commonplace", as one of the earlier quoted scientists would. Typically, scientists of the second type also highlight the fact that the molecular mechanisms for epigenetic inheritance are not sufficiently understood and that isolating and studying the responsible causal factors is experimentally challenging due to the abundance of potential confounding factors.

The differences in the above answers mark a crucial difference between two broad camps in the highly divers community of scientists engaged in epigenetic research. I suggest to call one group "phenomenologists" and the other "mechanists". Phenomenologists argue from the level of the observable phenomena (i.e. statistically robust correlations between observables), whereas mechanists tend to highlight the need for an understanding of the underlying molecular mechanisms that would provide a causal explanation for the observed correlations. In absence of such a mechanism, the latter argue, the existence of transgenerational epigenetic inheritance is at best plausible, but it cannot be considered a scientifically proven fact.

The frequently cited and widely discussed Oeverkalix study conducted and published under the supervision of the nutritional scientist and epidemiologist Lars Olov Bygren and the paediatric geneticist Marcus Pembrey in 2014 is a typical example of a phenomenologist approach to epigenetics. The study reported correlations between the fluctuation in food supply in grandparents and cardiovascular mortality in grandchildren in 277 families based on a statistical analysis of Swedish and Finnish local parish registers. The authors conclude that they have found an environmentally induced transgenerational effect. They do not propose a possible mechanism for the effect (Bygren et al. 2014). On the other hand, an example for a mechanistic approach to epigenetics is a study conducted by the group of plant biologist Ueli Grossniklaus already 20 years ago in which the researchers investigated the allel specificity of maternal DNA imprinting in the Arabidopsis MEDA gene and its effects on offspring development. (Vielle-Calzada et al. 1999).

From a methodological point of view, the two studies clearly differ. While the Oeverkalix study mainly included statistical methods from epidemiology applying a proportional hazards model to historical data sets, the MEDEA study employed 
standard methods of wet-lab biology such as in situ hybridisation, RT-PCR analysis and histological analysis.

Phenomenologists and mechanists also differ in their answers to the question: "How much impact does transgenerational epigenetic inheritance have on organisms?" (Grossniklaus et al. 2013, p. 9). While mechanists typically emphasize our extensive understanding of epigenetic molecular mechanisms in plants, phenomenologists are keen to highlight the importance of epigenetic inheritance in mammals. Here are the mechanists speaking:

[Quote 5 by a plant geneticist, who studies the genetic and molecular basis of plant reproduction]

One can easily imagine that it would be beneficial for plants, as sessile organisms, to take advantage of the information that they acquire about their environment and to pass it onto their progeny. The likelihood that the progeny will experience a similar environment is rather high, given that seeds are often dispersed locally. Thus, passing on such information to the progeny would have an adaptive value, and epigenetic inheritance is the prime candidate for its transmission. Indeed, plants have an extensive repertoire of epigenetic regulation involving mechanisms based on DNA methylation, histone modification and RNA.

[Quote 6 by a molecular biologist, who studies the epigenetic memory and reprogramming using $C$. elegans as model organism]

An argument against any potential lasting impact of epigenetic phenomena is that many of the processes are dynamic, and even the self-reinforcing or maintenance mechanisms have some inherent variability [...].

And here are two statements by phenomenologists:

[Quote 7 by a biomedical researcher, who studies the effects of protein folding on evolution and human disease]

The impact is enormous, in part because prions change cell biology in many, many different ways.

[Quote 8 by a pediatric geneticist, who studies environmental epigenomics and human transgenerational responses]

I wrote a commentary entitled 'Time to take epigenetic inheritance seriously'. Ten years on, I regard understanding human TGR [transgenerational response] as crucial, even if the eventual mechanisms do not meet the definition of transgenerational epigenetic inheritance that the purists demand!

Again, the phenomenologist in the last statement does not deny the fact that we are lacking a robust understanding of the molecular mechanisms underlying the epigenetic inheritance in mammals, but they nevertheless insist that the phenomenon exists and that it should be taken seriously. The statement also makes it clear that the division in (at least) two camps is not just an arbitrary artefact of the philosophical analysis proposed here, but that it coincides with the self-description of the involved researchers if established scientists feel inclined to distinguish themselves as not being among the "purists". 
It is also interesting to note that review articles often echo the skepticism of the mechanists, whereas discussions in public outlets show a tendency to take up the phenomologists' claims about the potential relevance of epigenetics for humans. It is reasonable to assume that this is due to the more consequential social implications that would follow from the phenomenologist's conclusions. A 2010 article (Cloud 2010) in Time Magazine, for instance, states the following:

[Quote 9] Bad news first: there's evidence that lifestyle choices like smoking and eating too much can change the epigenetic marks atop your DNA in ways that cause the genes for obesity to express themselves too strongly and the genes for longevity to express themselves too weakly.

The journalist supports his claims by reference to scientific literature:

[Quote 10] In February 2009, the Journal of Neuroscience published a paper showing that even memory-a wildly complex biological and psychological process - can be improved from one generation to the next via epigenetics.

And he goes on to imagine human control over epigenetic inheritance:

[Quote 11] DNA, we thought, was an ironclad code that we and our children and their children had to live by. Now we can imagine a world in which we can tinker with DNA, bend it to our will.

In comparison to such a language, the tone of a scientific review article (Heard and Martienssen 2014) is much soberer, highlighting the many reasons that exist to doubt the importance and stability of epigenetic inheritance in mammals. First and foremost, the review is critical with regards to the extent to which epigenetic inheritance might occur in humans:

[Quote 12] Although the inheritance of epigenetic characters can certainly occur-particularly in plants-how much is due to the environment and the extent to which it happens in humans remains unclear.

It is also highlighted that epidemiological studies are often not suited to rule out intergenerational effects:

[Quote 13] [M] ost of the studies so far concern intergenerational (parental or grandparental exposure) rather than truly transgenerational inheritance, and in most of the epidemiological studies, it has been difficult to rule out other effects such as the influence of postnatal nutritional environment and the use of cohorts where important covariates are missing.

Finally, it is questioned whether epigenetically inherited traits are actually adaptive and thus evolutionary preserved.

[Quote 15] Thus, although transmission of acquired states can occur in some animals (such as nematodes), proof that transgenerational inheritance has an epigenetic basis is generally lacking in mammals. Indeed, evolution appears to have gone to great lengths to ensure the efficient undoing of any potentially deleterious bookmarking that a parent's lifetime experience may have imposed. 
Summing up these observations, we can identify some general characteristics of the controversy between mechanists and phenomenologists in epigenetics. First, phenomenologists tend to depict epigenetic inheritance as a scientifically proven fact, not only in plants, but also in mammals. In order to support their claims they use an abductive inference: Epigenetic inheritance provides the best scientific explanation for correlations among certain observables that span two generations such as for example food supply for grandparents and cardiovascular health indicators in grandchildren. They believe that such inferences are warranted even if we have not yet elucidated the precise causal mechanism underlying epigenetic inheritance. Lack of molecular evidence is not seen as a sufficient reason to deny the reality of transgenerational epigenetic effects in mammals.

Mechanists, on the other hand, cast serious doubts on the existence of transgenerational inheritance in mammals, precisely because detailed causal knowledge of mechanisms is missing. They thus challenge the phenomenologists' inference to the best explanation. They do not rule out the possibility that there might be alternative explanations for the correlations of macroscopic observables, explanations that do not include reference to some sort of epigenetic inheritance pathway. They think that their challenge against the phenomenolgists' inference is justified even if they are unable to identify the correct alternative explanation. The fact that not all of the explanatory alternatives have been ruled out is sufficient for casting doubt on the existence of transgenerational epigenetic effects.

The controversy is thus not so much about the correctness of the available evidence. It is rather about the legitimacy of certain types of inferences that can be drawn from the evidence, i.e. whether certain types of evidence entitle to certain conclusions. In the case at hand, the controversial question is whether phenomenological evidence alone is sufficient to infer the existence of transgenerational epigenetic inheritance. Insofar as the evidence itself is under debate, it is so mostly because the available molecular evidence in mammals is of such a kind that it does not, according to the orthodox mechanists, allow to draw any inference on the temporal stability of the alleged epigenetic effects. When those who believe in the existence and importance of mammalian transgenerational inheritance present molecular evidence (e.g. involving studies of micro-RNAs in mice as in Gapp et al. 2014), critics point again at the gaps in the causal chain between the alleged causes at the molecular level and the stable transgenerational effect, the existence of which the evidence is supposed to establish. They argue that such studies typically do not rule out all possible confounding factors. Thus the debate is not so much about whether or not one should provide molecular evidence for epigenetic inheritance in mammals, but rather about what kind of molecular evidence warrants specific conclusions. Ultimately, the controversy boils down to two opposing views about the necessary degree of skepticism in the interpretation of the evidence. Mechanists clearly take the skeptic side in the debate.

Second, there appears to be a social aspect to the debate in the sense that the members of the two camps typically have different scientific socializations. Researches with a training in fields that related to the study of human health (biomedical science, epidemiology, neuroepigenetics) tend towards the phenomenologist side of the 
debate. Molecular biologists, biochemists or plant biologists, who are mainly interested in the study of molecular phenomena, seem to lean towards the mechanist side of the debate.

Third, scientific review articles tend to echo the mechanists' doubts, while public outlets frequently to take up the phenomenologists' claims about the potential relevance of epigenetic inheritance on human health.

\section{Benefits of perspectival practices}

The difference between the phenomenologist and the mechanist camp in current epigenetics, I argue, may be understood as a case of perspectivism. Furthermore, having different camps with different perspectives associated with different systems of practice, can be epistemically beneficial for the field as a whole.

However, the kind of perspectivism that we are facing in this debate cannot be interpreted in terms of perspectival models. It is not the case that the two camps are proposing different models for one and the same biological phenomenon. The conflict is not one between inconsistent models. It is rather a conflict between the perspectives of two groups of scientists with different scientific backgrounds and corresponding differences in their systems of practice. These differences become visible, for example, in the use of particular model organisms or experimental systems, in the focus on specific training or textbook knowledge, in the adoption of specific explanatory or methodological standards, or in common publication strategies. Most importantly, the two groups can be characterized in terms of varying epistemic priorities. While the phenomenologists seem to be interested in elucidating the potential impact of epigenetically induced effects on human health, the mechanists are primarily focused on understanding causality on the cellular and molecular level. Such differences of scientific practice can, I claim, lead to differences in the evaluation of the validity of specific inferences drawn from the available evidence.

It is crucially important to note, however, that, if applied to an individual scientist, the situation is rarely as clear-cut as the simple mechanist/phenomenologist distinction might suggest. Of course, many researches working in epidemiology or biomedical science are well-trained in molecular methods and frequently apply them in their research. Likewise, molecular biologists or biochemists might very well be able to appreciate the importance of epidemiological and statistical evidence when it comes to the study of epigenetic phenomena. It is also possible that an individual scientist remains undecided about whether epigenetic inheritance in mammals exists or not. Or they might change their opinion over the course of time or when taking into account previously unknown evidence. So the mechanist/phenomenologist distinction suggested here has to be taken with a grain of salt. It does not come with hard criteria that would allow for the allocation of each individual researcher to one of the camps.

The distinction is thus better understood as a distinction between perspectives in the strict sense. An individual can adopt a perspective or not, and perspectives can be changed under different circumstances. Yet in the version of perspectivism advocated here, the perspectives themselves are characterized not only with respect to 
theoretical stances, but also in terms of differences in practices. Furthermore, a full description of the practices and sociological differences underlying the perspectives involved in the case presented above would require a much more refined sociological analysis than can be provided in this article. It is conceivable that the result of such an analysis would be a more fine-grained description including more than two perspectives. The analysis might also include the study of differences in explanatory standards and ontological commitments between mechanistic explanations in today's molecular genetics and more holistic and dynamic approaches in epigenetics (as suggested by Baedke 2018).

Differences between perspectives can also be captured by differences in what Naomi Oreskes calls "epistemological affinities". In a similar vain as the present case study (though based on more detailed historical evidence), in her book The Rejection of Continental Drift (1999) Oreskes has analyzed the controversy around Alfred Wenger's theory of continental drift in the early decades of the $20^{\text {th }}$ century (Oreskes 1999; see also Oreskes 2008). Oreskes shows how the evaluation of Wenger's theory by fellow scientists "was pervasively interwoven in a fabric of epistemic, cultural, and social considerations" and that "[o]ne cannot understand any individual scientist's epistemic position vis à vis drift without understanding the cultural and social vectors that defined that position" (Oreskes 2008, p. 256). She calls the epistemic, cultural and social considerations that influence scientists' judgements "epistemological affinities", because they express themselves epistemologically in terms of different weightings of evidence. Oreskes also stresses that the sources of the differences in epistemological affinities "were largely social" and integral to the scientific practices of the individual scientists (Oreskes 1999, p. 53). But they must not be considered as "external" factors that are somehow imposed on the scientists from domains outside of their research. Quite on the contrary, epistemic affinities they can be the sources of important epistemic differences between rivaling camps in scientific controversies, and, as Oreskes has shown for the case of plate tectonics, they can even lead to the delayed acceptance of valuable, and eventually widely accepted scientific theories.

This constitutes a further reason for associating varying scientific practices that are shaped and influenced by epistemic affinities with perspectives. To treat scientific practices, or rather the differences between systems of practices due to epistemic, methodological, cultural and social differences as perspectives helps to realize that such differences are an integral part (and maybe even necessary part) of discovery processes. They are not merely external disturbances that disrupt the rational and objective scientific process of drawing conclusions from evidence. Diverging systems of practice constitute perspectives on reality. They shed light on open research questions from different vantage points and thus help to describe and understand the phenomena under scrutiny in a variety of possible ways.

At this point an overlap with Massimi's account of perspectival models emerges. Just like perspectival models have a modal function in exploring what is possible within a target system, perspectival practices are modal in the sense that they guarantee the exploration of various theoretical and experimental possibilities through which the phenomenon under scrutiny can be approached. However, in the case of epigenetics described above, the modal aspect of the perspectives does not extend to 
ontological possibilities. The two camps in the controversy do not argue about what entities, structures or processes might exist or not. Their contention is not about realism. It is about setting the limits for conclusions that can be drawn from the available evidence.

One could object at this point that the controversy described above is just a simple case of transient empirical underdetermination that does not require some sort of perspectivist analysis. Once we have collected additional evidence, e.g. about molecular mechanisms responsible for epigenetic inheritance in mammals, the dispute will be settled and there will be no room for varying perspectives on the question how much epigenetic inheritance takes place in humans. So the situation is simply reflective of the fact that many empirical questions remain open in current epigenetics and that the answers to fundamental questions are underdetermined by the available evidence. In such a situation, it is no surprise that scientists interpret the available evidence in different ways and that they reach diverging conclusions. The case presented above should thus be better described as a debate over epistemic warrant given various types of evidence rather than a case of opposing perspectives.

Although the objection is factually adequate in the sense that it would be perfectly possible to describe the situation in current epigenetics in terms of evidential warrant for causation, as has been frequently done in the literature in other contexts (see e.g. Illari et al. 2011 or Gillies 2018). It is also true that the history of science is full of debates that became settled once additional evidence became available, and the described controversy might also be resolved in such a manner sometime in the future. The objection nevertheless misses the point. Philosophical discussions about epistemic warrant for causal claims often exclusively focus on purely epistemic factors in the reconstruction of historical cases. This is of course highly legitimate, since these factors are usually important ingredients to the controversy and a rigorous philosophical analysis of such factors is crucial. However, the point of the above case study was neither to engage in a discussion about evidential warrant for causality in epigenetics nor to take sides in the controversy. The main argument for framing the debate in terms of perspectivism was precisely that perspectivism opens up a possibility to combine epistemic and social aspects in the description of scientific controversies. A purely epistemic approach cannot provide reasons for why different types of evidence are produced by different camps creating a situation in which the epistemic warrant for certain causal claims becomes controversial in the first place. In the perspectivist account proposed above, varying perspectives due to differences in the practices and socializations of the involved scientists are teated as reasons why different camps produce different types of evidence. Such an approach implies the inseparability of disagreements about evidential warrants for causal claims from the underlying social factors that induce those disagreements.

In fact, the benefits of perspectival practices come to bear precisely in situations where the answers to important theoretical questions are underdetermined by the evidence. These benefits are best captured by what Hasok Chang has called "benefits of co-optation" for interacting systems of practice (Chang 2012, pp. 280ff.). The crucial point here is to acknowledge that each perspective has internal constraints that can only be overcome by co-opting ideas, concepts, methods, or results from competing perspectives. 
One might argue that such constraints and differences between systems of practice are destructive to discovery processes in epigenetics and elsewhere, because overly mechanistic approaches or prevailing explanatory standards could constrain less orthodox research frameworks. However, diverging systems of practice within a field of research do not necessarily have to be detrimental. The idea of co-optation and the account of perspectival practices advocated for in this paper allows to ascribe a positive role to diverging systems of practice and to disagreement in science in general. Disagreement can be epistemically valuable, not only because it fosters critical discussion and forces each camp into clearer articulation, as classical accounts have it (e.g. Mill or Popper), but also because each side of the controversy is associated with particular data and evidence that leads to specific insights, which can be useful to the entire domain. ${ }^{4}$ In developing fields like epigenetics, where the answers to many theoretical questions are empirically underdetermined, adherence to a particular scientific camp is often not justified by evidence and rational argument alone but is likewise driven by the epistemic affinities and interests of the involved scientists, as was described above. In this sense, scientific controversies do in fact often involve an "apparent element of arbitrariness", to use Thomas Kuhn's infamous expression (Kuhn 1962, p. 4). However, differences in the epistemological affinities of different camps in a field of research can have an epistemically valuable function, because they lead to the production of various types of evidence and enable co-optation in Chang's sense.

Therefore, the presence of diverging perspectives does not render the process of knowledge generation as a whole irrational. This claim implies that trust in the rationality of science does not necessarily have to be grounded in consensus, and that disagreement in form of contrary but interacting perspectives plays an important role in scientific discovery processes. This result lends support to perspectivism as a valid philosophical position that explains how scientific knowledge is generated and why trust in science is justified even in the absence of a community consensus.

Acknowledgments The author thanks Michela Massimi for the opportunity to contribute to this topical issue. This paper was presented at the 2019 EPSA conference in Geneva and in a colloquium of the Lake Geneva Biological Interest Group at the University of Geneva. The author thanks the members of both audiences for their discussions and valuable feedback. Two anonymous reviewers have provided helpful comments to an earlier draft.

Funding Open access funding provided by University of St.Gallen.

Open Access This article is licensed under a Creative Commons Attribution 4.0 International License, which permits use, sharing, adaptation, distribution and reproduction in any medium or format, as long as you give appropriate credit to the original author(s) and the source, provide a link to the Creative Commons licence, and indicate if changes were made. The images or other third party material in this article are included in the article's Creative Commons licence, unless indicated otherwise in a credit line to the material. If material is not included in the article's Creative Commons licence and your intended use is not permitted by statutory regulation or exceeds the permitted use, you will need to obtain permission directly from the copyright holder. To view a copy of this licence, visit http://creativecommonshorg/licenses/by/4.0/.

\footnotetext{
${ }^{4}$ I am here following an account of disagreement that has originally been proposed by Miriam Solomon; see (Solomon 2001a, b, 2006).
} 


\section{References}

Baedke, J. (2018). Above the gene, beyond biology: toward a philosophy of epigenetics. Pittsburgh: University of Pittsburgh Press.

Bird, A. (2007). Perceptions of epigenetics. Nature, 447, 396-398.

Burbank, L. (1906). The training of the human plant. New York: Century Co.

Bygren, L.O., Tinghög, P., Carstensen, J., Edvinsson, S., Kaati, G., Pembrey, M.E., Sjöström, M. (2014). Change in paternal grandmothers' early food supply influenced cardiovascular mortality of the female grandchildren. BMC Genetics, 15, 1-6.

Chakravartty, A. (2010). Perspectivism, inconsistent models, and contrastive explanation. Studies in History and Philosophy of Science Part A, 41(4), 405-412.

Chang, H. (2012). Is water H2O? Evidence, realism and pluralism. Dordrecht: Springer.

Chang, H. (2020). Pragmatism, perspectivism, and the historicity of science. In Massimi, M., \& McCoy, C.D. (Eds.) Understanding perspectivism (pp. 10-27). New York: Routledge.

Cloud, J. (2010). Why your DNA isn't your destiny. Time Magazine.

Felsenfeld, G. (2014). A brief history of epigenetics. Cold Spring Harbor Perspectives in Biology, 6(1), $1-10$.

Gapp, K., Jawaid, A., Sarkies, P., Bohacek, J., Pelczar, P., Prados, J., Farinelli, L., Miska, E., Mansuy, I.M. (2014). Implication of sperm RNAs in transgenerational inheritance of the effects of early trauma in mice. Nature Neuroscience, 17(5), 667-669.

Giere, R.N. (2006). Scientific perspectivism. Chicago: University of Chicago Press.

Giere, R.N. (2013). Kuhn as perspectival realist. Topoi, 32(1), 53-57.

Gillies, D. (2018). Causality, probability and medicine. London: Routledge.

Grossniklaus, U., Kelly, W.G., Ferguson-Smith, A.C., Pembrey, M., Lindquist, S. (2013). Transgenerational epigenetic inheritance: how important is it? Nature Reviews Genetics, 14(3), 228-235.

Haecker, V. (1918). Entwicklungsgeschichtliche Eigenschaftsanalyse (Phänogenetik): Gemeinsame Aufgaben der Entwicklungsgeschichte Vererbungs- und Rassenlehre. Fischer: Jena.

Heard, E., \& Martienssen, R.A. (2014). Transgenerational epigenetic inheritance: myths and mechanisms. Cell, 157(1), 95-109.

Illari, P.M., Russo, F., Williamson, J. (2011). Causality in the sciences. Oxford: Oxford University Press.

Kuhn, T.S. (1962). The structure of scientific revolutions. Chicago: The University of Chicago Press.

Leitch, H.G., Tang, W.W.C., Surani, M.A. (2013). Primordial germ-cell development and epigenetic reprogramming in mammals. In Heard, E. (Ed.) Epigenetics and development, (Vol. 104 pp. 149-187). San Diego: Academic Press.

Massimi, M. (2018a). A perspectivalist better best system account of lawhood. In Ott, W., \& Patton, L. (Eds.) Laws of nature (pp. 139-157). Oxford: Oxford University Press.

Massimi, M. (2018b). Perspectival modeling. Philosophy of Science, 85(3), 335-359.

Massimi, M. (2018c). Perspectivism. In Saatsi, J. (Ed.) The Routledge handbook of scientific realism. New York: Routledge.

Massimi, M. (2018d). Points of view: Kant on perspectival knowledge. Synthese. https://doi.org/10.1007/ s11229-018-1876-7.

Massimi, M., \& McCoy, C.D. (Eds.) (2020). Understanding perspectivism: scientific challenges and methodological prospects. New York: Routledge.

Monk, D. (2015). Germline-derived DNA methylation and early embryo epigenetic reprogramming: the selected survival of imprints. The International Journal of Biochemistry and Cell Biology, 67, 128138.

Morrison, M. (2011). One phenomenon, many models: inconsistency and complementarity. Studies in History and Philosophy of Science Part A, 42(2), 342-351.

Nagel, T. (1986). The view from nowhere. Oxford: Oxford University Press.

Oreskes, N. (1999). The rejection of continental drift: theory and method in American earth science. Oxford: Oxford University Press.

Oreskes, N. (2008). The devil is in the (historical) details: continental drift as a case of normatively appropriate consensus?. Perspectives on Science, 16(3), 253-264.

Riggs, A.D., \& Porter, T.N. (1996). X-chromosome inactivation and epigenetic mechanisms. In Russo, E., Martienssen, R., Riggs, A. (Eds.) Epigenetic mechanisms of gene regulation (pp. 231-248). Cold Spring Harbor: Cold Spring Harbor Laboratory Press. 
Saatsi, J. (2020). Realism and explanatory perspectivism. In Massimi, M., \& McCoy, C.D. (Eds.) Understanding perspectivism (pp. 65-84). New York: Routledge.

Solomon, M. (2001a). Consensus in science. In Cao, T.Y. (Ed.) The proceedings of the twentieth world congress of philosophy, (Vol. 10 pp. 193-204). Bowling Green OH: Philosophy Documentation Center.

Solomon, M. (2001b). Social empiricism. Cambridge: MIT Press.

Solomon, M. (2006). Groupthink versus the wisdom of crowds: the social epistemology of deliberation and dissent. The Southern Journal of Philosophy, 44(S1), 28-42.

Stotz, K., \& Griffiths, P. (2016). Epigenetics: ambiguities and implications. History and Philosophy of the Life Sciences, 38(4), 22.

Teller, P. (2020). What is perspectivism, and does it count as realism?. In Massimi, M., \& McCoy, C. (Eds.) Understanding perspectivism (pp. 49-64). New York: Routledge.

van Fraassen, B.C. (2008). Scientific representation: paradoxes of perspective. Oxford: Oxford University Press.

Vielle-Calzada, J.P., Thomas, J., Spillane, C., Coluccio, A., Hoeppner, M.A., Grossniklaus, U. (1999). Maintenance of genomic imprinting at the Arabidopsis medea locus requires zygotic DDM1 activity. Genes and Development, 13(22), 2971-2982.

Waddington, C.H. (1942). The epigenotype. Endeavour, pp 18-20.

Weismann, A. (1892). Das Keimplasma. Eine Theorie der Vererbung. Jena: Verlag Gustav Fischer.

Publisher's note Springer Nature remains neutral with regard to jurisdictional claims in published maps and institutional affiliations. 